Clinical Medicine

Poster

Abstract ID: 137

\title{
Contraception use and its associated factors among grand multipara mothers in Kuantan
}

\author{
Che Azunie Che Abdullah | Azlina Daud | Aisyah Ismail \\ Kulliyyah of Nursing, International Islamic University Malaysia
}

Introduction: Pregnancy and childbirth bring health risks for women, and it is magnified in grand multipara mothers. Effective practice of contraceptive is important in spacing out childbirth to ensure both mother and child acquire optimum quality of life. Thus, with increasing number of grand multipara mothers who would face a greater reproductive risk, it is crucial to have a better understanding of their reproductive health. This study aimed to determine the contraceptive use and to identify associated factors influencing contraceptive use among grand multipara mothers in Kuantan. Methods: A descriptive cross sectional study was carried out in Klinik Kesihatan Ibu dan Anak Jaya Gading using purposive sampling. 49 respondents had been selected. The data of this study were analyzed and transformed by using statistical software. Results: The prevalence of contraceptive use among grand multipara mothers was 51\%. Grand multipara mothers who had high level of knowledge $(p=0.030)$ regarding contraceptive, positive attitude $(p=0.017)$ toward contraceptive use and having discussions with the spouse on contraception $(p=0.008)$ were more likely to use contraception. There was no statistically significant difference between the practice of contraceptive use and occupation $(p=0.175)$ or number of living children $(p=0.250)$. However, in this study, we found a statistically significant association between the contraceptive use and educational level $(p=0.036)$. Conclusions: The prevalence of contraceptive use in this study compared relatively low to other studies. Effective health promotion programs need to be done to encourage the practices of contraceptive.

KEYWORDS: Contraceptives, prevalence, contraceptive use, associated factors, grand multipara mothers 